\title{
Cognitive Restructuring Techniques (Crt) In Reducing Career Women's Anxiety
}

\author{
Norsuraya Hassan \& Syed Mohamad Syed Abdullah \\ School of Educational Studies Universiti Sains Malaysia, 11800 Penang, Malaysia. \\ norsuraya@usm.my
}

\begin{abstract}
This study aims to identify the level and symptoms of anxiety experienced by the subject. This study is also conducted to identify the effect of Cognitive Restructuring Techniques (CRT) to reduce the anxiety level experienced by the subject. It utilises a combination of the qualitative and quantitative method (mixed method) and the design of the study focuses on a single case study. The sample was obtained through the purposive sampling, where the subject was selected based on the characteristics that are desired in this study. The Beck Anxiety Inventory-Malay (BAI-Malay) was used to determine the level of anxiety experienced by the subject during the Pre-test, Post Test I, Post Test II and Post Test III. The analysis methods used for qualitative data in this study include observation, transcripts and document analysis. Meanwhile, the descriptive analysis (percentage) was also used for the quantitative data. The results showed that there is a change in the BAI-Malay score of 30.16\% (the difference scores of Pre-test and Post Test III) and at the end of the counseling session, the anxiety experienced by the subject was found to be at low level. Observation and transcripts analysis found that the symptoms of anxiety identified are positively reduced at the end of the session. This finding shows that the CRT is moderately effective in reducing the anxiety level of the subject and making the subject more positive in their daily lives.
\end{abstract}

Keywords: Cognitive restructuring techniques, anxiety, career women.

\section{INTRODUCTION}

Anxiety is a mental health disorder that often occurs and gives a significant burden to individuals and also to the country as a whole. Anxiety disorder is a mental disorder with different classes of severity of symptoms and disabilities (Baxter, Scott, Vos et al., 2013). It is among the sixth highest cause of the loss of capabilities recorded in the entire world, especially in high-income countries and middle-income countries. (Wong, Yip, Mak et al., 2016). Globally, anxiety disorder affects about $7.3 \%$ of the population but varies according to gender, culture, conflict, age and economic status (Baxter et al., 2013).

Anxiety is characterized by feelings of tension and anxiety which constitute a common process in life. However, if anxiety worsens or begins to affect the function of a person's life, it can be categorized as a disorder or disease (Nutt, de Miguel \& Davies, 2008). The types of anxiety include separation anxiety disorder, selective mutism, specific phobia, social phobia, panic disorder, agoraphobia and general anxiety disorder (GAD), (Baxter et al, 2013).

Often anxiety disorders are almost twice as common in women $(5.2 \%)$ than men $(2.8 \%)$. Adults aged 20-64 were noted to have higher anxiety disorders $(5.0 \%)$ than among other age groups (Baxter, Vos, Scott et al., 2014). Although there are wide variations in the prevalence of anxiety disorders, it is found to have an impact on the mental well-being of the population (Wiltink, Beutel, Till et al., 2011) as well as a significant deterioration in one's quality of life (Rapaport, Clary, Fayyad et al., 2005).

Career women play an important role in the family, community and country. Most women in Malaysia have been involved in employment. In addition to paying attention to, and perform their role in, the family, women also have to perform a variety of other tasks and to commit to their career. It's not a surprise why women are more prone to have anxiety symptoms compared to men (Baumeister \& Harter, 2007). In return, anxiety disorders experienced by the women can disrupt their daily lives and work performance.

Some of the physical symptoms of anxiety disorders are dizziness, fatigue, strong heartbeat, fast or irregular (palpitations), muscle aches and tension, trembling, dry mouth, excessive sweating, shortness of breath, stomachache, headache and difficulty in falling asleep and maintaining sleep (insomnia). Psychological anxiety symptoms are fear, feeling extravagance, difficulty in concentrating and irritability (National Institute of Mental Health, 2016).

In counseling therapy, various techniques can be applied to help individuals who experience this anxiety disorder including Cognitive Restructuring Techniques (CRT). The term cognitive restructuring has been used to describe the schematic change mechanism as described in Cognitive Therapy. CRT refers to the structure, therapeutics collaborative approach in which the individual is taught how to identify, evaluate, and modify the wrong idea/ thinking and then make a judgment and 
believe that the thinking is considered responsible for the psychological disorders faced by them (Dobson \& Dozois, 2010).

While there are many researchers worlwide that have studied the symptoms and effectiveness of this Cognitive Restructuing Technique for anxiety, the research is still scarce in Malaysia. Hence, this research is expected to assist in providing input on the anxiety symptoms and the effectiveness of the CRT in reducing the anxiety level experienced by the individual. It is crucial because failure in identifying anxiety symptoms and applying the effective technique for reducing anxiety will cause the individual's mental health problems such as depression, to worsen.

\section{METHODOLOGY}

This study utilises a combination approach or specifically the qualitative and quantitative method (mixed method) and the design of the study focuses on a single case study. The sample was obtained through purposive sampling, where the subject was selected based on the characteristics that are desired in this study. As for the research duration, it was conducted during the months of March to June 2017. In this study, the selected subject was among the female patients who attended a psychiatric clinic located in Penang, Malaysia who are undergoing an anxiety treatment.

The background of the subject was identified and checked through the patient's file. In addition to the administration of the pre-test (Beck Anxiety InventoryMalay) to determine the level of anxiety, the subject has also been diagnosed with anxiety by the doctor. Through the data obtained, subjects were selected for this study because it has complied with the features that are required in this study. The subject has also voluntarily agreed to participate in this study.

The subject is a 32-year-old woman, the 10th child out of 11 siblings, a Malay and Muslim. The subject is married and has 3 children. She is also a goverment servant who has been working for 9 years. The subject experienced several significant incidents in her previous life - subject and husband were threatened to be stabbed by the robbers and she also had lost both of her parents in succession the same year. These events make the subject feel traumatized and afraid of losing her loved ones. The subject is experiencing anxiety and fear that the same thing will happen and this in turn disrupts her daily life and work.

The method of collecting data is through the administration of the questionnaire, observation, verbatim (transcript of the session) and also from the documentation of patient's file. In this study, Beck Anxiety Inventory - Malay (BAI-Malay) is used to measure the subject's anxiety level. BAI-Malay is the translated version of the original BAI (Beck \& Steer, 1990) and it was developed by Firdaus Mukhtar \& Nor Sheereen Zulkefly (2011). It is a self-reported inventory of 21 items and has the reliability and validity to measure the anxiety level with Cronbach's alpha $(\alpha)$ coefficient between .66 and .89 with satisfactory overall alpha values (.91). BAI-Malay is also found to have acceptable concurrent validity.

The scoring method uses the Likert Scale with the overall score for all the items ranging between 0 and 63 points. Table 1 describes the level of anxiety by the total score, according to Beck, Epstein, Brown, et al. (1988).

\begin{tabular}{ll}
\multicolumn{2}{c}{ Table 1: Levels of Anxiety by Total Score } \\
\hline Total Score & Anxiety Level \\
\hline $\mathbf{0}-\mathbf{2 1}$ & Mild \\
\hline $\mathbf{2 2}-\mathbf{3 5}$ & Moderate \\
\hline $\mathbf{3 6}-\mathbf{6 3}$ & Severe \\
\hline Source: Beck, Epstein, Brown, et al., 1988
\end{tabular}

Data were also obtained through unstructured observations and focused questions based on the Mental Status Examination (MSE). MSE is an important part of the assessment process to evaluate the subject's mental state. It is a structured way of observing and describing the subject's psychological functions at a particular point in time under the domains of appearance, attitudes, behaviors, moods and affects, speech, thought process, content of thought, perception, cognition, insight and judgment (Trzepacz \& Baker, 1993).

Figure 1 explains the procedure of the study conducted. Each session is recorded with the subject's consent and converted into the form of verbatim to facilitate the analysis of the data. Through this verbatim the symptoms of anxiety and the effectiveness of CRT can be identified based on the themes built. Documentation data is obtained from patient's file with the permission to collect background data, symptoms of anxiety experienced by the subject as well as other relevant data and the current treatment received by the subject at the clinic.

The quantitative data was analyzed by comparing the BAI-Malay scores based on the Pre-Test, Post Test I, Post Test II and Post Test III to determine the level of anxiety experienced by the subject. For qualitative data, the observation analysis, verbatim content analysis and document analysis (patient files) were conducted to identify the anxiety symptoms and the effectiveness of CRT. Content analysis was carried out by getting to know the theme of the anxiety symptoms. The triangulation of data between test scores, observations and verbatim had been done to verify that the information obtained is accurate and reliable so as to determine the effectiveness of interventions carried out on the subject. 


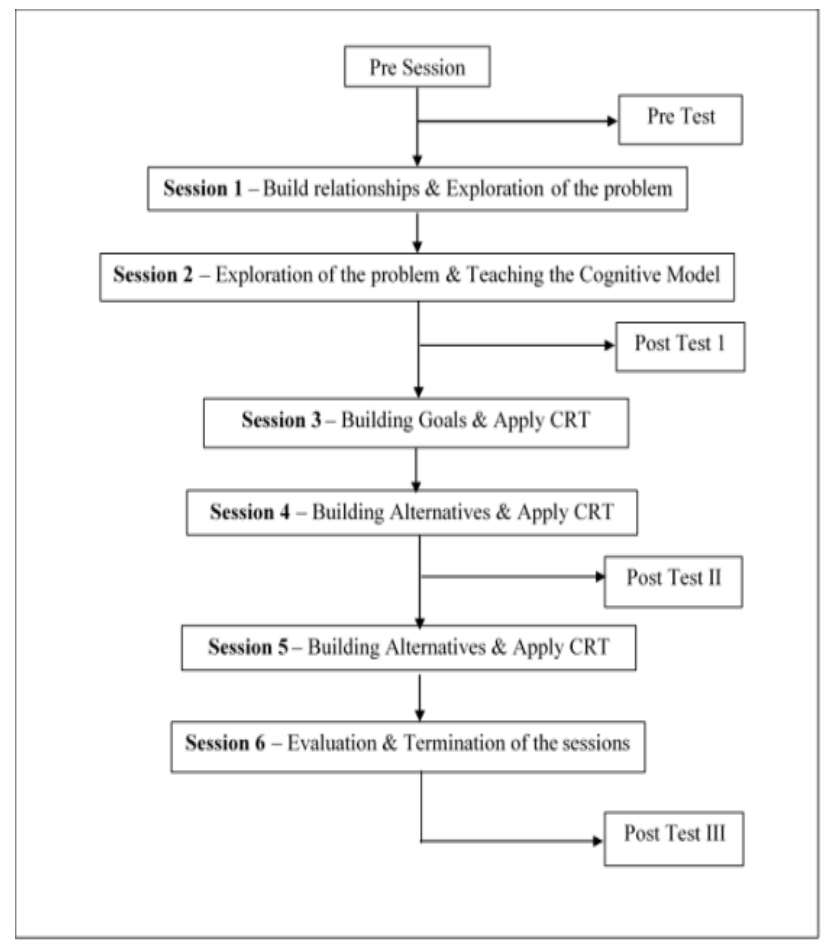

Figure 1: Research Procedure

\section{RESULTS}

\section{A. Anxiety Level Analysis}

Table 2 shows the BAI-Malay Pre-Test, Post Test I, Post Test II and Post Test III scores during the presession, also the second, fourth and sixth counseling sessions. Pre-Test score is 27 which shows that it is a moderate level of anxiety. This score is used as a baseline to identify anxiety level changes in the next test. Post Test I showed a decrease in score (21) which is at the stage of mild anxiety. The subject's anxiety level continued at the mild level with the Post Test II and Post Test III scores illustrating a decrease in scores of 13 and 8 respectively.

\begin{tabular}{|c|c|c|c|c|c|}
\hline Test & Score & & $\begin{array}{l}\text { Score } \\
\text { Differen } \\
\text { ce }\end{array}$ & $\begin{array}{l}\text { Percenta } \\
\text { ge } \\
\text { differenc } \\
\text { e }(\%)\end{array}$ & $\begin{array}{l}\text { Anxiet } \\
\text { y Level }\end{array}$ \\
\hline Pre-Test & 7 & 2 & 0 & 0 & $\begin{array}{l}\text { Modera } \\
\text { te }\end{array}$ \\
\hline Post Test I & 1 & 2 & 6 & 9.52 & Mild \\
\hline $\begin{array}{c}\text { P } \\
\text { Post Test II }\end{array}$ & 3 & 1 & 8 & 12.70 & Mild \\
\hline $\begin{array}{r}\text { P } \\
\text { Post Test III }\end{array}$ & & 8 & 5 & 7.94 & Mild \\
\hline
\end{tabular}

\section{Anxiety Symptoms Analysis}

i) Transcript Analysis

Anxiety symptoms of the subjects are divided into several themes, namely physical, emotional and behavioral symptoms. Figure 2 shows the symptoms of anxiety experienced by the subject based on the transcript analysis.

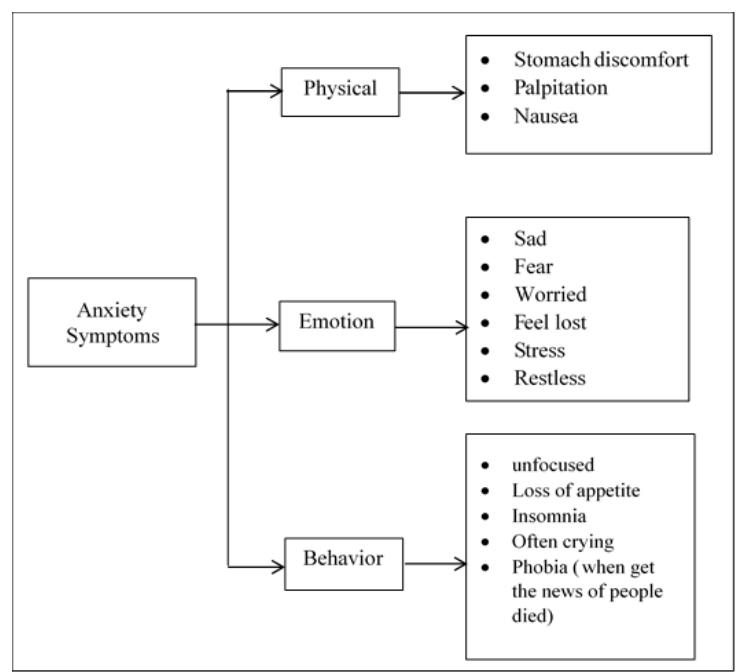

Figure 2: Anxiety Symptoms

ii) Observation Analysis

An observational analysis was conducted to determine the anxiety symptoms experienced by the subject and also to assess the mental status of the subject. Mental Status Examination (MSE) is used as a guideline to assess 11 important domains namely appearance, attitude, behavior, mood and affection, speech, thinking process, content of thinking, perception, cognition, insights and judgment. Based on the observation during the the first until the sixth session, it was found that the attitude, perception, cognition, insight and judgement domains are in a good and normal condition. Observation results also found that the appearance of the subject in the first session was less manageable but improved over time. Also for the behaviour domain, it is noticed that the subject had less eye contact during the first and second sessions.

Based on the observation under the mood and affect domains, it was found that the subject's anxiety is reducing from one session to the next. At the beginning of the session, the subject's speech was loud, rapid and emotional but during the third and subsequent sessions, the speech was clear and calm. From the observation of the thought process domain, the subject had shown her circumstantial thinking throughout the first until the third sessions. The thought content domain also shows that the subject was experiencing a simple phobia (fearful of hearing news about death) that started from the early session towards the end. Overall, through the observations using MSE it was found that the subject experienced a good improvement towards the end of the sessions.

iii) Document Analysis

The document analysis found that the subject has met the psychiatrist twice in the year 2017. The subject has 
been diagnosed by the psychiatrist as having "Adjustment Disorder with Anxiety" as a result of stress. It was recorded in the document that the subject experienced a panic attack when she heard about another person's death and also when she was separated from her husband. According to the document, the subject also experienced a sudden weight loss of $2 \mathrm{~kg}$ in a week from $113 \mathrm{~kg}$ to $111 \mathrm{~kg}$.

\section{B. CRT Effectiveness Analysis}

The effectiveness of CRT in reducing the anxiety experienced by the subject can be identified through the triangulation of data involving the BAI-Malay test scores, verbatim and also observation. Triangulation is also done to verify that the information obtained is accurate and reliable. BAI-Malay test scores show a consistent decline beginning from Post Test I until Post Test III. The difference of percentage of each BAI-Malay test score is shown in Graph 1.

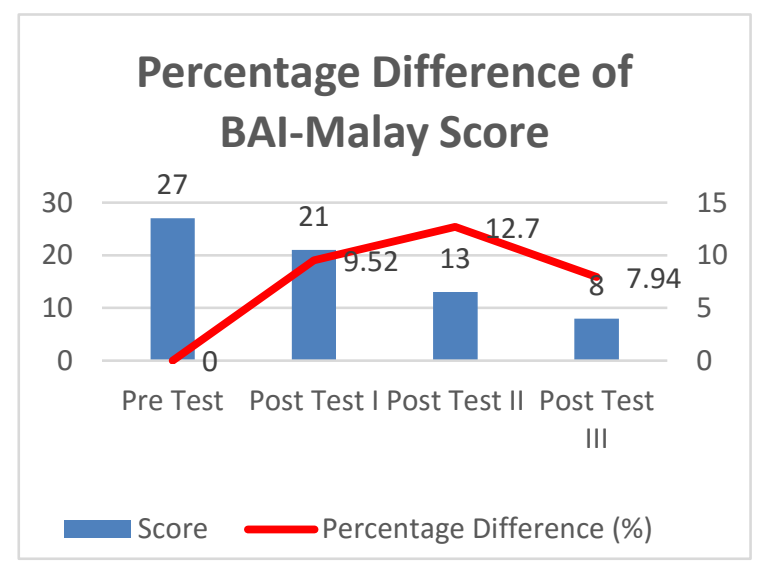

Graf 1: Percentage Difference of BAI-Malay Score Graph 1 shows the percentage of difference of the BAIMalay scores between Pre-Test and Post Test I, Post Test I and Post Test II also Post Test II and Post Test III. The analysis result showed that the percentage differences between Pre-Test and Post Test I scores is 9.52\%, between Post Test I and Post Test II the score is $12.7 \%$, and between Post Test II and Pos Test III the score is $7.94 \%$. The total difference of percentage between PreTest and Post Test III scores is $30.16 \%$. Based on Table 3 below, the total percentage difference is in the range of $26-50 \%$ which indicates that the change level is moderate.

Table 3: Change Level based on Total Percentage Difference

\begin{tabular}{|c|c|}
\hline $\begin{array}{c}\text { Total Percentage } \\
\text { Difference }\end{array}$ & Change Level \\
\hline$<\mathbf{2 5 \%}$ & Low \\
\hline $\mathbf{2 6 \%}-\mathbf{5 0 \%}$ & Moderate \\
\hline $\mathbf{5 1 \%}-\mathbf{7 5 \%}$ & Slightly High \\
\hline$>\mathbf{7 5 \%}$ & High \\
\hline
\end{tabular}

Source: Mohamad Hashim Othman (2014)
Based on the verbatim, it was found that CRT was effective in reducing subject's anxiety level (Session 6: line 24) besides helping the subject to become more positive in her daily life (Session 6: line 26). From the observations it is also found that the subject had undergone a good progress from time to time based on the 11 domains of MSE. Based on the triangulation of the quantitative data, observation and verbatim analysis it can be concluded that CRT interventions are effective in reducing the level of anxiety even at the moderate level of change.

\section{DISCUSSION}

The consistent decline of the BAI-Malay test scores that started from Post Test I until Post Test III (Table 1 \& Graf 1) showed a reduction in the level of anxiety experienced by subjects after the 6 counseling sessions conducted. The anxiety level during the Post Test I, Post Test II and Post Test III showed a mild level compared to moderate level during the Pre-Test. This indicates that eventhough the CRT has not been applied during the second session, as the results from a good relationship, trust is built on the researcher and the therapeutic environment created in the counseling sessions has helped in reducing the subject's level of anxiety.

At the beginning of the session, it is noticed that the subject had less eye contact, probably because she had yet to form a good rapport with the researcher. During sessions 1 and 2 which involve the process of building a relationship and exploring into problems, researchers have applied the basic skills of counseling, which are listening and entertaining skills, showing empathy, focusing on the subject and also doing paraphrase and reflecting on the feelings. These applied skills have made the subject feel comfortable and believe in the researcher, thereby helping in the treatment process to reduce the anxiety experienced by the subject. According to Rogers (1961), the client's progress in counseling relies heavily on three facilitating conditions of empathy, respect and kindness and also genuineness.

Based on the observations of the mood and affect domains, the subject shows anxiety, stress and sadness caused by the anxiety. It can be seen through the facial expressions and crying behavior at session 2 . These symptoms have also been expressed by the subject in the counseling sessions (Session transcript 1: lines 40, 72 \& 62). As the session is still very much about the reseaarcher exploring into the issue, the subject had so many things to share and express her feelings to mitigate the anxiety she had been feeling.

The subject also experiences anxiety behavior symptoms which include less focus on work, loss of appetite and insomnia (Session transcript 1: lines $101 \&$ 74). Due to the anxiety problem, the subject experienced insomnia because she always thought of negative and irrational things. This makes the subject experience fatigue and drowsiness thus disturbing her focus on work the next day. This may also cause the subject's 
appearance to be less manageable. An analysis of patient's documents also showed a sudden weight loss from $113 \mathrm{~kg}$ to $111 \mathrm{~kg}$ within a week due to the loss of appetite caused by her feelings of anxiety.

Circumstantial thinking demonstrated by the subject in the first session until the third session shows that the subject has a lot of irrelevant details of thought and she also makes frequent distortion of thoughts. Circumstantial thinking often occurs in individuals with anxiety disorders and some types of personality disorders (Sims, 1995; Trzepacz, Paula, Baker et al, 1993). The observation on the thought content domain found that the subject is experiencing simple phobia, fear of hearing news about death because of many negative thoughts that had surfaced and this makes the subject experience anxiety.

Through the observation and transcripts session, various subject-specific anxiety symptoms including physical symptoms (eg abdominal distress, palpitations), emotions (eg: sadness, worry, depression), behavior (eg: Often crying, not focus, no appetite, cannot sleep) and circumstantial thinking and simple phobia have been noted. All the symptoms of this anxiety arise as a result of the negative automated thinking experienced by the subject. Therefore, CRT is important to change the subject's thinking style so that the problem of anxiety can be addressed, thus reducing the above symptoms. The physical, emotional and behavioral anxiety symptoms described above are as consistent as the National Institue of Mental Health (2016).

CRT applications that have been done since session 3 have left a good and positive impact on the subject's anxiety level. By doing this technique the subject can identify the negative thoughts that she experienced, take up the challenge and replace it with a more positive and realistic thinking after being taught by the researcher. McLeod (2008) states that negative and unrealistic thinking can cause individuals to feel distressed and cause problems because of their way in interpreting a situation which becomes more defective, which in turn has a negative impact on the actions taken. Thus, CRT is helpful in changing the subject's thinking style to reduce the level of anxiety experienced.

Based on the transcripts of the session, the subjects also provided positive feedback on the CRT's impact as it greatly assisted the subject and made the subject more positive in her daily life (Session Transcript 6: lines 24, $26,74 \& 76)$. In addition, the subject's anxiety symptoms were also mentioned to be on the decrease after implementing the CRT (session 6 transcripts: lines 8 \& 10). This is because CRT is easy to understand, practical and easy for self-application which can be done by the subject at any time when he or she is experiencing negative thinking. From the observation using the MSE, there was also a positive change in the appearance, mood and affects, speech and thinking process domains after the application of CRT to the subject. The commitment that has been demonstrated by the subject has also increased the effectiveness of the CRT.

\section{CONCLUSION}

It has been proposed that such studies can be carried out by the other researchers in the future by focusing on the different subjects of the background such as socioeconomic status, education level, gender, family position, residence location, spiritual involvement and so on. This is to identify the symptoms and the effects of CRT use on the various backgrounds of anxiety subjects more widely. Such study periods may also be extended within sufficient time so that the percentage increase in the level of anxiety changes can be seen at a maximum level

Overall, CRT is an effective way in reducing the anxiety which is consistent with the findings of previous studies (Bouchard, Gauthier, Laberge et.al, 1996; Margraf \& Schneider, 1991). It has been able to assist in reducing the subject's anxiety even at moderate level of changes. However, this technique should be supported by other factors such as through the development of good relationships between subjects and researchers, beliefs towards the researcher, as well as therapeutic environment which indirectly contributes to the reduction of the subject's anxiety level. This CRT application has provided some awareness and understanding to the subject in dealing with the negative thoughts so that the subjects can live their daily lives more positively.

\section{REFERENCE}

Baumeister, H., \& Härter, M. (2007). Prevalence of mental disorders based on general population surveys. Social Psychiatry and Psychiatric Epidemiology42 (7), 537-546.

Baxter, A. J., Vos, T., Scott, K.M., Ferrari, A. J., \& Whiteford, H. A. (2014). The global burden of anxiety disorders in 2010. Psychological Medicine 44, 2363-2374.

Baxter, A. J., Scott, K. M., Vos, T., \& Whiteford, H. A. (2013). Global prevalence of anxiety disorders: a systematic review and meta-regression. Psychological Medicine43 (5), 897-910.

Beck, A. T., \& Steer, R. A. (1990) Manual for the Beck Anxiety Inventory. San Antonio, TX: Psychological Corporation 1990.

Beck, A. T., Epstein, N., Brown, G., \& Steer, R. A. (1988). An inventory for measuring clinical anxiety: psychometric properties. Journal of Consulting and Clinical Psychology56, 893-897.

Bouchard, S., Gauthier, J., Laberge, B., French, D., Pelletier, M. H., \& Godbout, C. (1996). Exposure versus cognitive restructuring in the treatment of panic disorder with agoraphobia. Behaviour Research and Therapy 34, 213-224.

Dobson, K. S., \& Dozois, D. J. A. (2010). Historical and philosophical bases of the cognitivebehavioral therapies. In K. S. Dobson (Ed.), Handbook of cognitive-behavioral therapies (3rd ed., pp. 3-38). New York, NY: Guilford Press.

Firdaus, M. \& Noor Sheereen, Z. (2011). The Beck Anxiety Inventory for Malays (BAI-Malay): A Preliminary 
Study on Psychometric Properties. Malaysian Journal of Medicine and Health Sciences 7(1), 73-79.

Margraf, J., \& Schneider, S. (1991). Outcome and active ingredients of cognitivebehavioral treatments for panic disorder. Paper presented at the 25th Annual Meeting of the Association for the Advancement of Behavior Therapy, New York.

McLeod, S. A. (2008). Cognitive Behavioral Therapy (Updated 2015). Accessed via www.simplypsychology.org/cognitive-therapy.html on $05 / 04 / 2017$

Mohamad Hashim Othman (2014). The effect of individual counseling interventions on drug addicts. Paper presented in the Drug Abuse Seminar PEMADAM, Perlis

National Institute of Mental Health (2016). Anxiety Disorders. Accessed https://www.nimh.nih.gov/health/topics/anxietydisorders/index.shtml on 05/04/2017.

Nutt, D., de Miguel, B.G., \& Davies, S.J.C. (2008). Phenomenology of anxiety disorders. Handbook of Behavaviour Neuroscience17(07), 365-393.

Rapaport, M. H., Clary, C., Fayyad, R., \& Endicott, J. (2005) Quality of life impairment in depressive and anxiety disorders. American Journal of Psychiatry 162, $1171-1178$.

Rogers, C. R. (1961). On becoming A Person. Boston: Houghton Mifflin Co.

Trzepacz, P. T., \& Baker, R.W. (1993). The Psychiatric Mental Status Examination. Oxford, U.K.: Oxford University Press. ISBN 0-19-506251-5.

Sims, A. G. (1995). Symptoms in the mind: an introduction to descriptive psychopathology. Philadelphia: W.B. Saunders. ISBN 0-7020-1788-4.

Wiltink, J., Beutel, M.E., Till, Y., Ojeda, F.M., Wild, P.S., Münzel, T., Blankenberg, S., \& Michal, M. (2011). Prevalence of distress, comorbid conditions and wellbeing in the general population. Journal of Affect Disorder 130 (3), 429-37.

Wong, S. Y., Yip, B. H., Mak, W. W., Mercer, S., Cheung, E. Y., Ling, C. Y., Lui, W. W., Tang, W. K., Lo, H. H., Wu, J. C., Lee, T. M., Gao, T., Griffiths, S. M., Chan, P. H., Ma, H.S. (2016) Mindfulness-based cognitive therapy v. group psychoeducation for people with generalised anxiety disorder: randomised controlled trial. British Journal of Psychiatry209 (1), 68-75. 